University of South Florida

DIGITAL COMMONS

Digital Commons @ University of

@ UNIVERSITY OF SOUTH FLORIDA

South Florida

USF St. Petersburg campus Faculty

Publications

USF Faculty Publications

2020

\title{
Leapfrogging at work: influencing higher levels in the chain of command
}

\author{
Sharon Segrest \\ University of South Florida St. Petersburg, ssegrest@mail.usf.edu \\ Martha C. Andrews \\ Scott W. Geiger \\ University of South Florida St. Petersburg, geiger@mail.usf.edu \\ Dan Marlin \\ University of South Florida St. Petersburg, marlind@mail.usf.edu \\ Patricia G. Martinez
}

See next page for additional authors

Follow this and additional works at: https://digitalcommons.usf.edu/fac_publications

\section{Recommended Citation}

Segrest, S.L., Andrews, M.C., Geiger, S.W., Marlin, D., Martinez, P.G., Perrewé, P.L. and Ferris, G.R. (2020), "Leapfrogging at work: influencing higher levels in the chain of command", Personnel Review, 49(8):

1769-1786. https://doi.org/10.1108/PR-07-2019-0382

This Article is brought to you for free and open access by the USF Faculty Publications at Digital Commons @ University of South Florida. It has been accepted for inclusion in USF St. Petersburg campus Faculty Publications by an authorized administrator of Digital Commons @ University of South Florida. For more information, please contact digitalcommons@usf.edu. 


\section{Authors}

Sharon Segrest, Martha C. Andrews, Scott W. Geiger, Dan Marlin, Patricia G. Martinez, Pamela L. Perrewe, and Gerald R. Ferris 


\section{Leapfrogging at work: influencing higher levels in the chain of command}

\author{
Sharon L. Segrest \\ Kate Tiedemann College of Business, University of South Florida St. Petersburg, \\ St. Petersburg, Florida, USA \\ Martha C. Andrews \\ Department of Management, University of North Carolina Wilmington, Wilmington, \\ North Carolina, USA \\ Scott W. Geiger and Dan Marlin \\ Kate Tiedemann College of Business, University of South Florida St. Petersburg, \\ St. Petersburg, Florida, USA \\ Patricia G. Martinez \\ Department of Management, Loyola Marymount University, Los Angeles, \\ California, USA, and \\ Pamela L. Perrewé and Gerald R. Ferris \\ Florida State University, Tallahassee, Florida, USA
}

\begin{abstract}
Purpose - Acts of interpersonal influence are observed throughout organizations, and most typically, in direct supervisor-subordinate relationships. However, researchers have focused less on subordinates bypassing the chain of command and targeting their supervisor's supervisor with influence attempts. We conceptualize a new term, "leapfrogging," as subordinates' attempts to influence and manage the impressions of their supervisor's supervisor. Here we focus on influencing the target's perception of likability (the focus of ingratiation) and competence (the focus of self-promotion). This study focuses on its personal and situational antecedents.

Design/methodology/approach - Given the central role of social exchange and psychological processes within this phenomenon, we build on a social exchange and a social cognition approach. Using a sample of 131 university support personnel service employees, hierarchical regression is used to test the hypotheses.

Findings - The following antecedents of leapfrogging are hypothesized and tested: the subordinate personal characteristics of Machiavellianism, need for achievement, and fear of negative evaluation, and the situational/ relational characteristic of leader-member exchange (LMX). Of these potential antecedents, subordinate Machiavellianism and LMX were the strongest predictors, and subordinates' need for achievement and fear of negative evaluation were moderate predictors.

Practical implications - Leapfrogging occurs when actors are frustrated with their current situation and desire change. However, influence tactics aimed at a subordinate's supervisor's supervisor may further strain a low-quality leader-subordinate relationship. As actors become increasingly dissatisfied and leave, this may result in increased organizational costs related to the loss of experienced employees and the hiring and training of new ones.

Originality/value - Most upward influence research has largely ignored subordinate influence attempts that go outside of the normal chain of command and target their boss's boss. The present study addresses this gap in the literature by examining leapfrog behaviors. Although acknowledged in a limited manner as a legitimate organizational behavior, this topic has received virtually no empirical attention.
\end{abstract}

Keywords Leapfrogging, Influence tactics, Leader-member exchange (LMX), Social exchange theory, Vertical influence behavior, Machiavellianism

Paper type Research paper
Leapfrogging Behavior at Work

Received 19 July 2019 Revised 13 October 2019 19 November 2019 14 December 2019 Accepted 15 January 2020 
PR

49,8

\section{Introduction}

Social influence processes represent one of the oldest areas of investigation in the social and organizational sciences, dating back to Triplett's (1898) classic study. Since then, scholars have examined different forms or tactics of influence including ingratiation, self-promotion, and coalition building (e.g., Ferris et al., 2002). More recently, researchers have framed and studied voice (Burris, 2012; Detert et al., 2013) and social networks (Bolander et al., 2015; Fang et al., 2015; Grosser et al., 2018; Sparrowe and Emery, 2015) as additional forms of influence.

Furthermore, most research has focused on influence tactics aimed upward and directed at one's immediate supervisor, reflecting the typical organizational structure, operational forms of interpersonal engagement, and "chain of command" (Ferris et al., 2002; Long et al., 2015).

Thus, although we know quite a lot about forms, mechanisms, and directions of influence, there remain important but largely ignored areas of inquiry (Ferris et al., 2019; Westphal and Stern, 2006). Farrell and Petersen (1982) referred to one of these areas as vertical influence behavior, which occur when employees bypass the normal chain of command, skipping a level and bypassing their own boss, and instead, directing influence attempts at their boss's boss. Ferris and Hochwarter (2011) echoed this appeal for additional inquiry when they argued that scholars need to go beyond subordinate-supervisor, and supervisor-upper management influence effects, and examine subordinate-upper management effects. The present study responds to these appeals, focusing on influence attempts intentionally directed toward the supervisor above one's direct supervisor. We call this behavior "leapfrogging," and we address the directionality and intentionality of these influence behaviors. Furthermore, we attempt to identify the personal and situational antecedents of this type of influence behavior.

Specifically, we conceptualize leapfrogging as subordinates' intentional and focused attempts to influence and manage the impressions of upper-level management (specifically aimed at one's supervisor's supervisor). Our specific focus is those behaviors that influence the target's perception of likability (the focus of ingratiation) and competence (the focus of self-promotion). Historically, ingratiation and self-promotion have been the most frequently studied influence tactics in the field, and typically, the most effective (Ferris, et al., 2002; Jones, 1990). This is similar to the way individuals develop and leverage reputation in organizations. Research on this topic has determined that the two key dimensions of reputation are performance and character (e.g., Ferris et al., 2014). Performance and character could be roughly compared to the competence and likability factors we aim for here with leapfrogging.

The belief by subordinates is that as they increase upper managers' perceptions of their competence and character, their future influence attempts should be more successful. When developing a new construct, it is essential to establish that its conceptualization, definition, and measurement are internally consistent and valid, thus ensuring a strong "interplay between theory and method" (Van Maanen, Sorensen and Mitchell, 2007). When comparing the foregoing discussion of our conceptualization of the leapfrogging construct, with the measurement of leapfrogging in a later section, it can be seen that we took strong and decisive steps to ensure this interplay. It is also essential to establish the boundary conditions of this study, influence attempts focused on the target's perceptions of likability and competence. As such, we recognize that this type of leapfrogging behavior can be followed by leapfrogging behaviors which could include requests for favors, resources, and rewards. However, those are outside of the scope of our study.

This study is an initial attempt to define and explore the leapfrogging construct by exploring its potential antecedents. Consistent with the social influence literature, we investigate characteristics of the influencers (Machiavellianism, need for achievement, and fear of negative evaluation) and characteristics of the context (Leader-Member Exchange) to better understand leapfrogging behavior. Additionally, since previous research has found 
that a masculine communication style is related to career advancement (Weinberg et al., 2019), gendered communication could be a significant predictor of leapfrogging. Specifically, assertiveness, a form of upward influence commonly associated with masculine communication, has been positively related to perceptions of subordinates' promotability (Wayne et al., 1997). Although it was not a focus of this study, we include sex as a control variable.

\section{Similarities to and differences from other areas of the literature}

Because we conceptualize leapfrogging as both similar to and different from other forms of influence, we propose antecedents in our hypothesis development that are similar to other influence tactics, and some that are unique to this form of influence. Thus, although we argue that leapfrogging behavior has not been addressed directly, existing theory and research discusses how employees might work outside the formal structures of organizations in order to maximize their goal attainment, and we draw from this literature.

Additionally, we must acknowledge that the research on social structure, formal and informal social networks, the exercise of voice mechanisms in reaction to organizational conditions, and individual mutuality considerations in supervisor-subordinate relationships (e.g., Brass and Krackhardt, 2012; Detert et al., 2013; Dulebohn et al., 2012; Dabos and Rousseau, 2004; Dobrow et al., 2012; Fuller et al., 2007; Martin et al., 2018; Weinberg, 2019) has potential implications for leapfrogging behavior. Indeed, the literature on social structure and influence has discussed the ways that individuals can exercise influence through network positioning outside the formal organization structure (e.g., Brass and Krackhardt, 2012).

A significant amount of that work overlaps with our conceptualization of leapfrogging behavior, because it acknowledges that organizations reflect both formal and informal structures, and employees often try to utilize these informal structures to operate outside of the often assumed mechanistic model of organizations (e.g., Stewart and Carson, 1997). Where our focus on leapfrogging behavior departs from this other work is that it reflects intentional, agentic, influence-focused, goal-directed behavior, which the other work does not. Furthermore, some of this work characterizes upward voice behavior from an impression management perspective, focused on image enhancement, and less concerned about producing real, substantive change (Fuller et al., 2007).

We acknowledge that our leapfrogging perspective is incompatible with a "mutuality perspective," where all members of a work unit or organization collaborate towards personal and professional goal attainment (e.g., Dobrow et al., 2012; Dabos and Rousseau, 2004; Weinberg, 2019). If we assumed that mutuality is a common characteristic of most organizations, then perhaps there would be a weaker rationale for our individual-focused influence construct. Instead, we view the mutuality perspective as an objective that organizations may be pursuing but not a reality for all. So, we believe there is a sound rationale for individually focused change efforts, as there are for active voice efforts (e.g., Detert et al., 2013).

When subordinates exhibit leapfrogging behaviors (i.e., directed at one's boss's boss) subordinates likely possess much less knowledge about this target than about their direct supervisor. Thus, we assess and characterize the leapfrogging construct as behavior aimed at developing a more generalized image that is characterized by competence and likability: the two most frequent and most effective influence tactics (Ferris et al., 2002; Jones, 1990). A much closer target (e.g., immediate supervisor) reflects a situation where subordinates would possess more knowledge about the target, and thus formulate and implement more focused and specific strategies of influence. However, leapfrogging behavior is not a redirected influence attempt that first failed when aimed at one's direct supervisor. The target all along is the supervisor's supervisor.
Leapfrogging Behavior at Work 
PR

49,8

Theoretical foundations and hypotheses development

Employees in organizations engage in leapfrogging behavior when they intentionally aim their influence attempts at their supervisor's supervisor in efforts to obtain resources which might include the ability to promote, provide salary increases, and change job responsibilities and work schedules. This paper specifically addresses the direct influence activity of bypassing the chain of command, or "leapfrogging," in an attempt to influence a target above the immediate supervisor (i.e., the supervisor's supervisor). These are employees' agentic, goal-directed behaviors intended to influence the positive perceptions of one's boss's boss. The broad and favorable impressions these employees seek to instill in higher-level managers are that they are likeable and competent, which are perceptions that are developed through the influence tactics of ingratiation and self-promotion.

Based on previous upward influence research, we propose that dispositional or individual characteristics of the actor (i.e., need for achievement, fear of negative evaluation, Machiavellianism) predispose someone to leapfrog (Barbuto and Moss, 2006; Bolino and Turnley, 2003; Chacko, 1990). Additionally, the contextual variable of leader-member exchange (LMX) may predict leapfrogging (Farmer and Maslyn, 1999). The better the quality of the LMX relationship, the less likely actors will bypass their direct supervisor and potentially harm this relationship by focusing their influence efforts at the supervisor's supervisor. These individual characteristics are not an exhaustive list of characteristics that may affect leapfrogging behavior. However, these are some of the most frequently mentioned characteristics in the relevant literature, and therefore, may be some of the most important (Barbuto and Moss, 2006; Bolino and Turnley, 2003; Tse et al., 2017).

Because actors' influence tactics occur in a social context, and they are based upon their perceptions of their supervisors and themselves, we rely on a social cognition theoretical foundation. Social cognition focuses on how individuals make sense of themselves and others while considering the role of individual and situational factors including attitudes, perceptions, and stereotyping (Fiske and Taylor, 1991; Pishwa, 2009). According to Bodenhausen and Hugenberg (2009), social cognition researchers generally believe that actors' behavioral responses are based upon their cognitive representation of themselves, others, and their corresponding contexts. A social cognition approach views actions and behaviors as social judgments.

Therefore, the underlying social information processing model for this view assumes that behaviors are the results of (a) perceptions, which lead to (b) cognitive representations of actors and their contexts (i.e., conception), which finally result in (c) action. This development of the leapfrogging concept identifies as antecedents the actor's personal characteristics and those of the situation and the actor-supervisor relationship including: the actor personal characteristics of Machiavellianism, need for achievement, and fear of negative evaluation are examined as predictors of leapfrogging. Additionally, we consider the situational/ relational characteristic of Leader-Member Exchange (LMX).

Personal/actor characteristic: Machiavellianism. The term Machiavellianism (Mach) was derived from The Prince by Niccolo Machiavelli, originally published circa 1532. Machiavelli's treatise on human behavior and the nature of rulers examined their cunning or deceitful political actions; however, it is regarded as highly applicable to the contemporary context. Individuals who rate high on this trait, "high Machs," are described as more manipulative and persuasive than "low Machs" (Galie and Bopst, 2006). Within the organizational research literature, Machiavellianism has been related to upward influence (Andersson and Bateman, 2000), and meta-analytic research has shown a strong relationship between Machiavellianism and the use of influence tactics (Barbuto and Moss, 2006). However, Barbuto and Moss (2006) called for additional research on Machiavellianism and upward appeals, because the cumulative sample size was less than 800 in the 11 studies included in their meta-analysis. 
Individuals who are high on Machiavellianism exhibit interpersonal interactions that are manipulative because they are willing to achieve goals by any means (Barbuto and Moss, 2006). High Machs are interested in advancing their own self-interests (Sibunruang and Capezio, 2016), and are more likely to exert upward influence (Farmer et al., 1997; Hochwater et al., 2000). Furthermore, recent research utilizing LMX and Machiavellianism found that when LMX is unfavorable, high Machs engage in more impression management behaviors than do low Machs (Tse et al., 2017). Hence, we hypothesize:

H1. Actors who are high in Machiavellianism will be more likely to leapfrog than actors who are low in Machiavellianism.

Personal/actor characteristic: need for achievement. Individuals with a high need for achievement aim for moderately challenging goals and react positively to competition (Mowday, 1978). Research has examined need for achievement in relationship to organizational issues such as attributional style, goal-setting, and career-related coping (Kalnbach and Hinsz, 1999; Rotondo, 1999). Converse et al. (2012) specifically discussed the impact of need for achievement in controlling one's environment and its implications for career success.

Individuals with a high need for achievement and success favor options involving a challenge as well as taking action to achieve a desired outcome, rather than leaving matters to chance. Treadway et al. (2005) viewed need for achievement as a willingness to take action, and found it was positively related to the use of influence. Indeed, some researchers have suggested individuals with a high need for achievement are more confident that their upward influence attempts will be successful (Tedeschi et al., 1972; Terpstra-Tong and Ralston, 2002). Furthermore, Schilit (1986) found that need for achievement was related to successful influence attempts aimed at immediate supervisors. Thus, we hypothesize that need for achievement predicts leapfrogging behavior.

H2. Actors with a high need for achievement will be more likely to leapfrog than actors with a low need for achievement.

Personal/actor characteristic: fear of negative evaluation. Fear of negative evaluation is the extent to which individuals feel apprehensive at the possibility of a negative evaluation by others (Leary, 1983). Those with a strong fear of negative evaluation act to avoid an unfavorable evaluation (Leary, 1983). Social anxiety arises when actors believe that they will produce the wrong impression, or that something embarrassing will happen (Sedikides et al., 2002). Thus, actors who engage in upward influence incur a risk that the target will view their desired image negatively. For example, self-promotion, and trying to be seen as competent, may come across as arrogant, particularly if actors do not self-promote effectively (Turnley and Bolino, 2001).

Leapfrogging may represent significant risk, because the target has more perceived power than the immediate supervisor. Not only does the actor risk negative evaluation by the target (i.e., the supervisor above one's immediate supervisor), but if the immediate supervisor becomes aware of being bypassed, retaliation may occur. Individuals differ with respect to their psychological reaction to risk. Those with a strong fear of negative evaluation are conservatively biased, and they attempt to avoid risk, while those with a weak fear of negative evaluation will not worry about the potential of upward influence backfiring (Turnley and Bolino, 2001). Thus, the following is hypothesized:

H3. Actors who have a weak fear of negative evaluation will be more likely to leapfrog than actors who have a strong fear of negative evaluation.

Situational/relational characteristic: leader-member exchange. Leader-member exchange (LMX) refers to the quality of the relationship individuals develop with their immediate supervisor (Dulebohn et al., 2012, 2017). High-quality LMX relationships are characterized by high levels of interaction, trust, and support from their supervisors (Dulebohn et al., 2012).
Leapfrogging Behavior at Work 
PR

49,8

1774

In contrast, low-quality LMX relationships are characterized by low levels of interaction, support, trust, and rewards from their supervisors. In managing a low-quality LMX relationship, the supervisor relies primarily on formal authority, rules, and policies.

Additionally, members of high-quality LMX relationships perceive a higher level of fairness than do those in low-quality LMX relationships (Erdogan and Enders, 2007; Wang et al., 2017). Those fortunate enough to be in high-quality LMX relationships are often involved in decision-making through their supervisor interactions (Sparr and Sonnentag, 2008). Moreover, LMX is positively related to the degree to which subordinates believe their supervisors provide them with needed resources (Piccolo et al., 2008).

Finally, the concept of social exchange (Blau, 1964; Levi-Strauss, 1969) is a key mechanism to understanding LMX, and how it may affect leapfrogging. Shore and Coyle-Shapiro (2003) proposed that many studies support social exchange as a basis for understanding employeeorganization relationships. Social exchange involves individuals' voluntary actions that are motivated by expected returns, as well as unspecified obligations and trust (Blau, 1964). Individuals reciprocate positive exchanges, such as trust and support, in their behaviors and attitudes.

Furthermore, this framework is particularly valuable because it considers both the tangible and economic benefits and the non-economic and symbolic value of exchanges, such as the economic and personal value of organizational resources, benefits, and development opportunities. Recently, Crawford et al. (2019) drew from social exchange theory to hypothesize that perceptions of organizational politics create an imbalance in the exchange relationship between the employee and the organization, which leads to organizational deviance. Thus, they similarly view social exchange as a foundational framework for examining how reciprocity, as a result of a negative exchange, can drive behaviors.

Hence, a high-quality LMX relationship will be negatively related to leapfrogging, because these in-group members have some control over the decisions that affect their jobs. These ingroup members believe that their supervisors can provide them with desired outcomes (e.g., pay increases, better job assignments), and they do not wish to potentially hurt this positive relationship. Supervisors could very well perceive leapfrogging behaviors as disloyal and hurtful to the relationship, particularly because subordinates circumvent their authority and appeal to a higher-level manager. As a result, we hypothesize that:

H4. Actors will be less likely to leapfrog when they perceive a strong leader-member exchange (LMX) relationship with their immediate supervisor than when they experience a low LMX relationship.

\begin{abstract}
Method
Sample

We utilized a list obtained from the human resource department of full-time university support service employees of a large university located in the southeastern United States. The sample size $(N=131)$ was comprised of 30 men and 98 women. Tenure with the university ranged from 1 to 36 years with a mean of 10.6 years with the university. The ages of the respondents ranged from 20 to 64 years old with an average age of 43.8 years. These employees held a variety of positions including clerical workers, managers, janitors, and groundskeepers with education level ranging from some high school to advanced degrees.
\end{abstract}

\title{
Procedure
}

We first obtained approval to collect the data from the university's Institutional Review Board. A paper-and-pencil questionnaire was sent to a random sample of 900 non-faculty employees via campus mail. A cover letter explained that responses would remain 
anonymous and confidential, and that we are human resource management researchers who are investigating different types of communication in the workplace. We enclosed an addressed return envelope and asked participants to complete the questionnaire during the next month and return it through campus mail. We also stated that by volunteering to complete and return the attached survey, respondents agree to participate in this research project and we included our contact information.

A total of 234 surveys were returned for a response rate of 26 percent. Our sample was further reduced to 131 due to missing data. There were no significant differences in demographics between those who responded and the population, thus, we did not find evidence for non-respondent bias.

\section{Measures}

All questions on the survey, excluding demographics, were measured using a five-point Likert-type scale. We describe the scale anchors within each section below. The items in each scale were averaged to create an overall mean for each concept, with higher scores reflecting higher degrees of each construct. Items that were not completed by the respondents were coded as missing values and excluded from the data analyses.

Leapfrogging. Four modified items from the MIBOS influence scale (Kumar and Beyerlein, 1991) measured how often respondents used ingratiation and self-promotion tactics aimed at those above their immediate supervisor. During the past decades, these two influence tactics have been the most frequently researched and they contribute to a generalized positive image of actors using such tactics (e.g., Ferris et al., 2002; Jones, 1990). This can correspond to individuals' reputation of high performance, competence, good character, and likeability (e.g., Ferris et al., 2014). Thus, as noted above, when developing a new construct, it is essential to establish that its conceptualization, definition, and measurement are internally consistent and valid (Van Maanen et al., 2007).

Respondents were asked to refer to the individual above their immediate supervisor when answering the following questions. The question stem stated: "How often (did) do you. ..?" The anchor on the low end was "Never do it" (1), "Occasionally do it (3)" and "Nearly always do it (5)." The four questions are as follows: (1) Try to let him/her know you have a reputation for being liked; (2) Try to make sure that he/she is aware of your successes; (3) Look for opportunities to let him/her know your virtues/strengths; and (4) Try to persuasively present your own qualities when attempting to convince him/her about your abilities. The reliability estimate for this scale was 0.89 .

Machiavellianism. Christie and Geis' (1970) Mach IV (Version 1) 10-item scale was used to measure the actor's level of Machiavellianism. A five-point Likert-type scale was used with the following anchors: "strongly disagree" (1) and "strongly agree" (5). Sample items include: "Anyone who completely trusts anyone else is asking for trouble" and "Generally speaking, people won't work hard unless they're forced to do so." The reliability estimate for this scale was 0.82 .

Need for achievement. Three items from the Need for Advancement scale and Advancement Opportunity scale of the Manifest Needs Questionnaire measured need for achievement (Steers and Braunstein, 1976). A five-point Likert-type scale was used with the anchor on the low end identified as "strongly disagree" (1) while the anchor on the high end was identified as "strongly agree" (5). Items included the following: "I do my best work when my job assignments are fairly difficult," "I try very hard to improve on my past performance at work," and "I take moderate risks and stick my neck out to get ahead at work." The alpha reliability for this scale was 0.73 .

Fear of negative evaluation. This variable was measured using Leary's (1983) 12-item Fear of Negative Evaluation Scale. A five-point Likert-type scale was used with the anchor on the

Leapfrogging Behavior at Work 
PR

49,8

low end identified as "strongly disagree," (1) whereas the anchor on the high end was identified as "strongly agree" (5). Representative items from this scale were: "I am usually worried about what kind of impression I make," and "I am frequently afraid of other people noting my shortcomings." The reliability estimate for this scale was 0.90 .

Leader-member exchange. The seven-item $L M X$ - seven scale (Scandura et al., 1986) was employed to measure the quality of the relationship employees perceived they shared with their supervisors. A five-point Likert-type scale was used with the following anchors: "strongly disagree" (1) and "strongly agree" (5). Sample items from this scale were: "My working relationship with my immediate supervisor is extremely effective," and "My immediate supervisor recognizes my potential." The internal consistency reliability for this scale was 0.91 .

Controlvariables. Differences in the usage and effectiveness of upward influence tactics have been related to sex (Guadagno and Cialdini, 2007; Turnley and Bolino, 2001). Therefore, sex was entered as a control variable in our data analyses ( $\operatorname{coded} 0=$ Men; $1=$ Women). We also found that race (coded $0=$ Minority and $1=$ White) and age could relate to subordinates' use of leapfrogging behavior, so these variables also were included as controls (Festekjian et al., 2014).

\section{Data analyses and results}

Descriptive statistics, correlations, and common method variance test

The correlations among the variables appear in Table Ialong with means, standard deviations, and alpha reliabilities. As shown in Table I, leapfrogging was significantly correlated with all of the predictor variables except need for achievement, and all of the correlations were in the expected directions. The Cronbach's alpha reliabilities ranged from 0.73 to 0.91 .

One interesting significant correlation was between age and fear of negative evaluation $\left(-0.169^{*}\right)$. As age increases, fear of negative evaluation decreases. One possible explanation is that tenure is related to age, and so those with longer tenure are more confident in their social standing. Another significant correlation $(\phi<0.10)$ was between LMX and fear of negative evaluation $(0.144+)$. As LMX increases, the fear of negative evaluation increases. It makes sense that those with a stronger relationship with their supervisor would be more concerned with the impression they make on their boss than those with a weaker relationship with their supervisor.

Surprisingly, sex was not correlated with leapfrogging. However, sex was correlated with need for achievement with men showing a higher need for achievement than women. This is consistent with previous research (Meece and Courtney, 1992), and Eccles (1987) explained differences in need for achievement between the sexes as due to choice, socialization, and cultural norms.

Common Method Variance (CMV) can occur when mono-method data are collected, reflecting single-source, self-report bias. Furthermore, Spector (2006) noted that CMV can lead to inflated correlations among variables. In order to address the CMV issue, we inspected the correlation matrix and found no correlations among the variables to be of concern. Next, we performed a Harman's one-factor test. A Harman's factor with variance explained over 0.5 suggests a substantial amount of common method variance (Podsakoff, et al., ,2003). The Harman's one-factor test indicated 0.19 variance explained, which is far below the threshold of concern. Therefore, in light of these results, we are confident that CMV did not impact the results of this study.

\section{Hypothesis testing}

Hierarchical regression was used to test the hypotheses using SPSS version 26 software to analyze the data. The results of the regression analyses appear in Table II. The control 


\begin{tabular}{|l|c|c|c|c|c|c|c|c|c|c|c|}
\hline \multicolumn{1}{|c|}{ Variable } & $M$ & $S D$ & 1 & 2 & 3 & 4 & 5 & 6 & 7 & 8 & \\
\hline 1. Leapfrogging & 1.34 & .70 & 1.000 & $(.89)$ & & & & & & & \\
\hline 2. Sex & .25 & .44 & -.034 & 1.000 & & & & & & & \\
\hline 3. Race & .68 & .47 & -.085 & $-.129+$ & 1.000 & & & & & & \\
\hline 4. Age & 42.93 & 10.67 & -.038 & .017 & .065 & 1.000 & & & & & \\
\hline $\begin{array}{l}\text { 5. LMX } \\
\text { 6. Machia- } \\
\text { vellianism }\end{array}$ & 3.29 & 1.07 & $-.240^{* *}$ & -.103 & .092 & -.038 & 1.000 & $(.91)$ & & & \\
\hline $\begin{array}{l}\text { 7. Need for } \\
\text { Achievement }\end{array}$ & 3.77 & .65 & .107 & $-.206^{* *}$ & $.205^{* *}$ & -.010 & $.136+$ & .013 & 1.00 & $(.73)$ & \\
\hline $\begin{array}{l}8 . \text { Fear of } \\
\text { Negative } \\
\text { Evaluation }\end{array}$ & 2.59 & .54 & $-.124+$ & .014 & .003 & $-.169^{*}$ & $.144+$ & $.119+$ & -.065 & 1.000 & $(.90)$ \\
\hline
\end{tabular}

Leapfrogging Behavior at Work

Note(s): $+p<0.10{ }^{*} p<0.05,{ }^{* *} p<0.01 ; N=131$

Reliabilities on the diagonal in parentheses

Race was coded $0=$ Minority; $1=$ White; Sex was coded $0=$ Men; $1=$ Women

Table I.

Means, standard deviations, reliabilities, and correlations of all variables

\begin{tabular}{|l|l|l|l|}
\hline Variable & $\begin{array}{c}\text { Hypothesis } \\
\text { Tested }\end{array}$ & \multicolumn{2}{c|}{$\begin{array}{c}\text { Leapfrogging } \\
B\end{array}$} \\
\hline & & \multicolumn{2}{|c|}{} \\
\hline Step 1 & & & \\
\hline Sex & & -.045 & \\
\hline Race & & -.089 & \\
\hline Age & & -.031 & \\
\hline$R^{2}$ & & & .010 \\
\hline Adjusted $R^{2}$ & & & -.013 \\
\hline & & & \\
\hline Step 2 & & -.067 & \\
\hline Sex & & -.112 & \\
\hline Race & & -.032 & \\
\hline Age & 1 & $-.203^{* *}$ & \\
\hline LMX & 2 & $.289^{* *}$ & \\
\hline Machiavellianism & 3 & $.132+$ & \\
\hline Need for Achievement & 4 & $-.125+$ & \\
\hline Fear of Negative Evaluation & & & $.176^{* *}$ \\
\hline$R^{2}$ & & & $.129^{* *}$ \\
\hline Adjusted $R^{2}$ & & & \\
\hline
\end{tabular}

Note(s): $+p<0.10,{ }^{*} p<0.05, * * p<0.01 ; N=131$

Table II.

Results of hierarchical regression

variables of sex, age, and race were entered in step 1, and in step 2, the variables of Machiavellianism, LMX, need for achievement, and fear of negative evaluation were entered.

As can be seen in Table II, Hypothesis 1 was supported $(\beta=0.289, p<0.01)$, indicating that subordinates who were high on Machiavellianism were more likely to leapfrog. Moderate 
PR

49,8

1778
Figure 1.

Interaction between LMX and Machiavellianism and their effects on leapfrogging support was found for Hypothesis $2(\beta=0.132, p<0.10)$, indicating that leapfrogging is more likely to occur when the subordinate has a high need for achievement. Hypothesis 3 was also moderately supported $(\beta=-0.125, p<0.10)$, indicating that subordinates with strong fear of negative evaluation are less likely to engage in leapfrogging. Hypothesis 4 was supported $(\beta=-0.203, p<0.01)$ in that subordinates were less likely to leapfrog when they perceived a strong LMX with their supervisors.

\section{Exploratory post-hoc analyses: person $\mathrm{x}$ situation interactions}

The main hypothesis tests drew from theory and research related to predictors of leapfrogging, including personal and situational characteristics. However, theory in the organizational sciences suggests that personal and situational characteristics can interact to predict behavior and attitudes in organizations. This body of theory and research is referred to as "person x situation interaction," or simply, "interactional psychology," and it examines the role of each part of the interaction process (e.g., Endler and Magnusson, 1976; Schneider, 1983; Terborg, 1981).

Based on this perspective, in an exploratory post-hoc manner, we examined the interaction of each personal/actor variable with the situational variable, LMX. For the Machiavellianism $\mathrm{x}$ LMX interaction, the results demonstrated a significant negative interaction $(\beta=-0.224$, $p<0.01$ ); for the need for achievement $x$ LMX interaction, the results showed no significant interaction $(\beta=-0.051, p=0.55)$; and for the fear of negative evaluation $\mathrm{x}$ LMX interaction, the results showed no significant interaction $(\beta=0.113, p=0.17)$. The significant interaction (i.e., Machiavellianism $x$ LMX), when plotted, indicated the situation (i.e., LMX) overrode the effect of the person variable (i.e., Machiavellianism). More specifically, moderate and high levels of LMX resulted in a negative relationship between Machiavellianism and leapfrogging. Under conditions of low LMX, Machiavellianism was slightly positively related to leapfrogging (see Figure 1).

\section{Discussion}

Overview of the research

We coined the term "leapfrogging" to describe a unique social influence behavior, and identified four theoretically relevant predictors. Results of this study suggest that the actor characteristics of Machiavellianism, need for achievement, and fear of negative evaluation, and the relational/situational characteristic of LMX may play a role in the propensity for

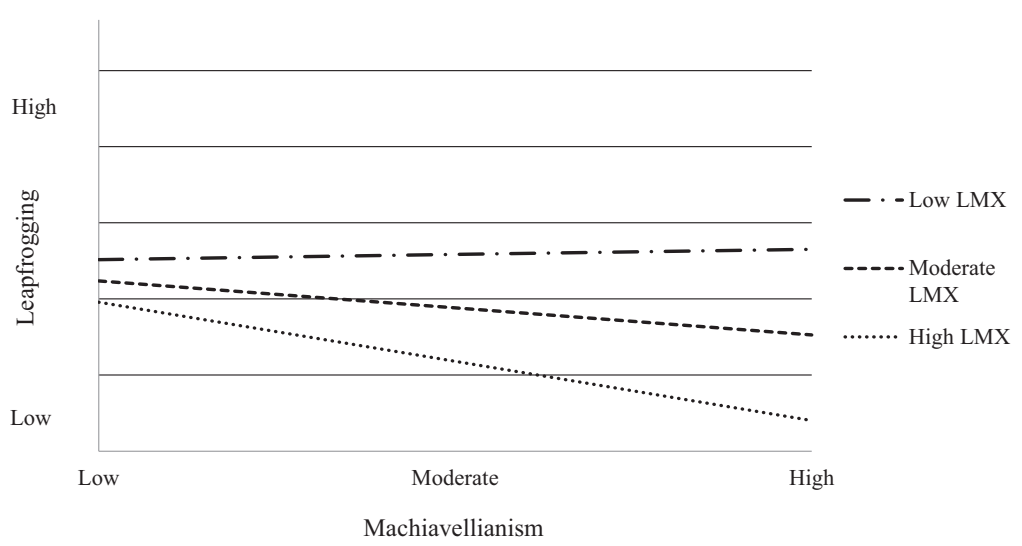


leapfrogging, although the effects were only moderate. Higher levels of Machiavellianism of the subordinate and lower levels of the situational characteristic of LMX lead to the highest demonstration of leapfrogging behavior.

Based on recent research using social comparison theory and Machiavellianism research (Tse et al., 2017), and the results of our study, we believe that if subordinates are frustrated enough by the denial of resources or other career-related conditions from their immediate supervisors, they may decide to leapfrog. This behavior reflects an exercise of influence a level above their direct supervisor, aimed outside the normal chain of command at their supervisor's supervisor. It particularly occurs when subordinates are high in Machiavellianism, and when they experience a low-quality LMX relationship with their immediate supervisor.

\section{Directions for future research}

The variables studied here are not an exhaustive list of predictors. However, these are among the most frequently mentioned in the literature (Barbuto and Moss, 2006; Bolino and Turnley, 2003; Tse et al., 2017), and therefore, are likely to be among the most important to consider. Furthermore, considering the social influence research literature, future research should include the actor individual-level variables of core self-evaluation, negative affectivity, self-monitoring, political skill, proactive personality, and emotional intelligence.

Future research should examine interactions among these aforementioned variables on leapfrogging. For example, in our post-hoc analyses, LMX moderated the effect of Machiavellianism on leapfrogging. When LMX was moderate or high, Machiavellianism was negatively related to leapfrogging. In this instance, the situation was more powerful than the individual as high LMX deterred leapfrogging. Additional situation x person interactions could be explored for their potential effects on leapfrogging.

Given that research demonstrates a positive relationship between masculine communication styles and upward advancement and promotions (Weinberg et al., 2019), future research should incorporate communication style with the use of upward influence (i.e., leapfrogging). For example, future research could focus on the effect of communication style differences, based on Bem's gender typology (1974), on leapfrogging behavior. Our study controlled for sex, but did not investigate potential differences in leapfrogging behavior based on masculine and feminine communication styles. Similar to our research, metaanalysis results have suggested that differences in communication styles between men and women are small (Hyde, 2005), and only 25 percent of the variance in gendered communication style is explained by biological sex (Weinberg et al., 2019).

A masculine communication style stereotypically has been associated with males, and has been described as assertive, ambitious, self-confident, dominant, forceful, self-reliant, and individualistic (Eagly and Carli, 2007). This authoritative style has been associated with selfpromotion and the leadership prototype (Casey, 2004; Wood et al., 1997). Meanwhile, the feminine communication style stereotypically has been associated with females, and has been described as sympathetic, cooperative, nurturing, friendly, encouraging, participative, kind, sensitive, and soft-spoken.

Based on these descriptions of the masculine and feminine communication and previous research on communication styles, one would expect that a masculine communication style, which includes self-promotion behaviors, would be more comfortable with leapfrogging behaviors. Those who typically use the feminine communication style and are more softspoken, sensitive, cooperative, and more likely to play by the rules, speak mainly to their immediate supervisor instead of self-promoting to a higher-level supervisor. This is a fertile area for future research, and ties in well with calls for research that go beyond asking what
Leapfrogging Behavior at Work 
PR

49,8

style, masculine or feminine, is preferred in the workplace, and how communication styles are used differently to obtain career outcomes (e.g., number of promotions, level of salary) (Weinberg et al., 2019).

Additionally, future research might consider examining the relational variable, interactional justice; situational variables of goal importance and perceptions of organizational politics; and the instrumental variable, expectations for success (Farmer and Maslyn, 1999; Ferris et al., 2007; Turnley, and Bolino, 2001). Finally, although our focus here is on influencing the supervisor above one's immediate supervisor, it is certainly plausible that these behaviors could be directed at superiors completely outside one's chain of command. This represents another potential area of future influence research.

Because bypassing the traditional chain of command and going over one's supervisor's head can be tricky, and needs to be managed well, we underscore future research on political skill. First, we believe political skill can predict leapfrogging behavior, with a potentially moderating role on the leapfrogging-work outcomes relationships (e.g., Munyon et al., 2015). With respect to work outcomes, our study examined the antecedents or predictors of leapfrogging behavior, not its consequences, which could include attitudinal (e.g., job satisfaction) and behavioral (e.g., citizenship behavior) outcome measures, as well as measures of career success.

Furthermore, we do not explore consequences originating from the immediate supervisors who were bypassed, for subordinates engaging in leapfrogging behavior. Therefore, an important direction for future research is to assess the consequences of leapfrogging behavior for individual leapfroggers, their direct supervisors, their supervisors' supervisors, and for organizations. If leapfrogging behavior leads to positive outcomes for individuals and organizations, will we want to discourage it?

Moreover, the target's (i.e., the supervisor's supervisor) characteristics, as well as the bypassed supervisor's characteristics, are likely to be important in determining leapfrogging behavior. These may include Machiavellianism of the immediate supervisor, and variables such as the target's perceived reward and coercive power, and these should be incorporated into future research. Additionally, there are many tangential opportunities for developing the leapfrogging concept in future research, such as incorporating organizational-level variables and examining other situational variables. For example, economic factors, the importance of the current job and employer, and opportunities for comparable jobs could affect how recklessly someone might behave with regard to bypassing the chain of command or leapfrogging around their current supervisor. In addition, different cultural contexts could be examined to see how important differences in cultural values (e.g., collectivism/individualism, power distance, and uncertainty avoidance) are in explaining leapfrogging behavior.

\section{Practical implications}

The phenomena of influencing targets above the immediate supervisor have received little research attention previously, yet, there are strong implications for managers and employees who engage in leapfrogging behavior. As the present paper and related research suggest (Tse et al., 2017), leapfrogging may occur as the result of an actor's frustration with the current situation, and a desire for change. When these desires are not met, the actor may become increasingly dissatisfied and eventually leave the organization, resulting in increased organizational costs related to loss of an experienced employee, and the costs associated with hiring and training of a new employee.

Attention should be paid to improving the quality of supervisor-subordinate LMX relationships in order to help prevent subordinates from feeling the need to leapfrog and bypass the chain of command to obtain resources. If subordinates feel that they are being treating fairly and receiving adequate amounts of communication, trust, opportunities to 
achieve, and appropriate recognition for their achievements, they are likely to reciprocate with returned trust, improved attitudes, and more positive behavioral outcomes (Piccolo et al., 2008). Making an effort to bring more subordinates into the in-group and involving them in participative decision-making will improve the overall LMX of a supervisor's subordinates as a group, and decrease the need for subordinates to leapfrog and bypass the chain of command (Sparr and Sonnentag, 2008).

Managers should be aware of leapfrogging and its antecedents, such as low LMX. Awareness and understanding of leapfrogging may help management prevent the necessity of this behavior, ultimately leading to increasingly satisfied employees as well as increased retention and improved performance. In addition, subordinate engagement in leapfrogging behavior can be risky, in terms of its potential impact on the quality of the relationship between the subordinate and the supervisor, so it has to be handled carefully and with finesse - or with political skill (Ferris et al., 2005).

Aside from the structural implications of employees bypassing formal reporting relationships and chain of command, future research should examine what are the outcomes of leapfrogging behavior, and whether it leads to more or less favorable outcomes. If future research finds that leapfroggers and organizations do not suffer negative consequences from leapfrogging behavior, but actually benefit from such behavior, then should organizations really discourage such behavior? Or, is it simply a matter of formal organization structural protocol to preserve the formal chain of command, and discourage leapfrogging behavior? Indeed, the issue has been discussed and debated for decades as to whether it sometimes is appropriate to bypass formal channels in organizations in order to get things done that need to be done, but are blocked or frustrated by formal channels. Future work should examine such issues.

\section{Conclusion}

Social influence processes in organizations have been studied for well over a century, representing one of the most frequently investigated phenomenon in the behavioral and organizational sciences. Unpacking this vast array of studies, we learn that many different types of influence tactics have been studied, aimed at a number of different targets of influence, in several different directions in the organizational hierarchy, with upward influence attempts by subordinates toward their immediate supervisors representing the most frequently studied form.

We coin the term "leapfrogging" behavior to refer to influence behavior aimed at one's supervisor's supervisor, and we formulate and test hypotheses regarding the antecedents of this type of influence. This is an initial attempt to study this new area of influence behavior, and we hope this effort stimulates scholars to continue work in this interesting and important area of social influence processes in organizations.

\section{References}

Andersson, L.M. and Bateman, T.S. (2000), "Individual environmental initiative: championing natural environmental issues in U.S. business organizations", Academy of Management Journal, Vol. 43 No. 4, pp. 548-570.

Barbuto, J.E. and Moss, J.A. (2006), "Dispositional effects in intra-organizational influence tactics: a meta-analytic review", Journal of Leadership \& Organizational Studies, Vol. 12 No. 3, pp. 30-48.

Bem, S.L. (1974), "The measurement of psychological androgyny", Journal of Consulting and Clinical Psychology, Vol. 42, pp. 155-162, doi: 10.1037/h0036215.

Blau, P.M. (1964), Exchange and Power in Social Life, Wiley, New York.
Leapfrogging Behavior at

Work 
PR

49,8

Bodenhausen, G.V. and Hugenberg, K. (2009), “Attention, perception and social cognition”, in Strack, F. and Förster, J. (Eds), Social Cognition: The Basis of Human Interaction, Psychology Press, New York.

Bolander, W., Satornino, C.B., Hughes, D.E. and Ferris, G.R. (2015), "Social networks within sales organizations: their development and importance for salesperson performance", Journal of Marketing, Vol. 79 No. 6, pp. 1-16.

Bolino, M.C. and Turnley, W.H. (2003), "More than one way to make an impression: exploring profiles of impression management", Journal of Management, Vol. 29 No. 2, pp. 141-160.

Brass, D.J. and Krackhardt, D. (2012), "Power, politics and social networks in organizations", in Ferris, G.R. and Treadway, D.C. (Eds), Politics in Organizations: Theory and Research Considerations SIOP Frontier Series Volume, Routledge/Taylor and Francis, New York, pp. 355-375.

Burris, E.R. (2012), "The risks and rewards of speaking up: managerial responses to employee voice", Academy of Management Journal, Vol. 55 No. 4, pp. 851-875.

Casey, C. (2004), "Contested rationalities, contested organizations: feminist and postmodernist visions", Journal of Organizational Change Management, Vol. 17, pp. 302-314.

Chacko, H.E. (1990), "Methods of upward influence, motivational needs, and administrators' perceptions of their supervisors' leadership styles", Group \& Organization Studies, Vol. 15 No. 3, pp. 253-265.

Christie, R. and Geis, F.L. (1970), Studies in Machiavellianism, Academic Press, Cambridge, MA.

Converse, P.D., Pathak, J., DePaul-Haddock, A.M., Gotlib, T. and Merbedone, M. (2012), "Controlling your environment and yourself: implications for career success", Journal of Vocational Behavior, Vol. 80 No. 1, pp. 148-159.

Crawford, W.S., Lamarre, E., Kacmar, K.M. and Harris, K.J. (2019), "Organizational politics and deviance: exploring the role of political skill”, Human Performance, Vol. 32 No. 2, pp. 92-106, doi: 10.1080/08959285.2019.159710.

Dabos, G.E. and Rousseau, D.M. (2004), "Mutuality and reciprocity in the psychological contracts of employees and employers", Journal of Applied Psychology, Vol. 89 No. 1, pp. 52-72.

Detert, J.R., Burris, E.R., Harrison, D.A. and Martin, S.R. (2013), "Voice flows to and around leaders: understanding when units are helped or hurt by employee voice", Administrative Science Quarterly, Vol. 58 No. 4, pp. 624-668.

Dobrow, S.R., Chandler, D.E., Murphy, W.M. and Kram, K.E. (2012), "A review of developmental networks: incorporating a mutuality perspective", Journal of Management, Vol. 38 No. 1, pp. 210-242.

Dulebohn, J.H., Bommer, W.H., Liden, R.C., Brouer, R.L. and Ferris, G.R. (2012), “A meta-analysis of antecedents and consequences of leader-member exchange: integrating the past with an eye toward the future", Journal of Management, Vol. 38 No. 6, pp. 1715-1759.

Dulebohn, J.H., Wu, D. and Liao, C. (2017), "Does liking explain variance above and beyond LMX? A meta-analysis", Human Resource Management Review, Vol. 27 No. 1, pp. 149-166.

Eagly, A.H. and Carli, L.L. (2007), "Women and the labyrinth of leadership", Harvard Business Review, Vol. 85, pp. 63-71.

Eccles, J.S. (1987), “Gender roles and women's achievement-related decisions”, Psychology of Women Quarterly, Vol. 11 No. 2, pp. 135-172.

Endler, N.S. and Magnusson, D. (1976), “Toward an interactional psychology of personality", Psychological Bulletin, Vol. 83 No. 2, pp. 956-974.

Erdogan, B. and Enders, J. (2007), "Support from the top: supervisors' perceived organizational support as a moderator of leader-member exchange to satisfaction and performance relationships", Journal of Applied Psychology, Vol. 92 No. 2, pp. 321.

Fang, R., Chi, L., Chen, M. and Baron, R.A. (2015), "Bringing political skill into social networks: findings from a study of entrepreneurs", Journal of Management Studies, Vol. 52 No. 2, pp. 175-212. 
Farmer, S.M. and Maslyn, J.M. (1999), "Why are styles of upward influence neglected? Making the case for a configurational approach to influences", Journal of Management, Vol. 25 No. 5, pp. 653-682.

Farmer, S.M., Maslyn, J.M., Fedor, D.B. and Goodman, J.S. (1997), "Putting upward influence strategies in context", Journal of Organizational Behavior, Vol. 18 No. 1, pp. 17-42.

Farrell, D. and Petersen, J.C. (1982), "Patterns of political behavior in organization", Academy of Management Review, Vol. 7 No. 3, pp. 403-412.

Ferris, G.R., Davidson, S.L. and Perrewé, P.L. (2005), Political Skill at Work: Impact on Work Effectiveness, Davies-Black, Mountain View, CA.

Ferris, G.R., Ellen, B.P. III, McAllister, C.P. and Maher, L.P. (2019), "Reorganizing organizational politics research: a review of the literature and identification of future research directions", Annual Review of Organizational Psychology and Organizational Behavior, Vol. 6, pp. 299-323.

Ferris, G.R., Harris, J.N., Russell, Z.A., Ellen, B.P. III, Martinez, A.D. and Blass, F.R. (2014), “The role of reputation in the organizational sciences: a multi-level review, construct assessment, and research directions", in Buckley, M.R., Wheeler, A.R. and Halbesleben, J.R.B. (Eds), Research in Personnel and Human Resources Management, Emerald Group Publishing Ltd, Bingley, UK, Vol. 32, pp. 241-303.

Ferris, G.R. and Hochwarter, W.A. (2011), "Organizational politics", in Zedeck, S. (Ed.), APA Handbook of Industrial and Organizational Psychology, American Psychological Association, Washington, DC, Vol. 3, pp. 435-459.

Ferris, G.R., Hochwarter, W.A., Douglas, C., Blass, R., Kolodinsky, R.W. and Treadway, D.C. (2002), "Social influence processes in organizations and human resources systems", in Ferris, G.R. and Martocchio, J.J. (Eds), Research in Personnel and Human Resources Management, JAI Press/ Elsevier Science, Oxford, UK, Vol. 21, pp. 65-127.

Ferris, G.R., Treadway, D.C., Perrewé, P.L., Brouer, R.L., Douglas, C. and Lux, S. (2007), "Political skill in organizations", Journal of Management, Vol. 33, pp. 290-320.

Festekjian, A., Tram, S., Murray, C.B. and Sy, T. (2014), "I see me the way you see me: the influence of race on interpersonal and intrapersonal leadership perceptions", Journal of Leadership \& Organizational Studies, Vol. 21 No. 1, pp. 102-119.

Fiske, S.T. and Taylor, S.E. (1991), Social Cognition, McGraw-Hill, New York.

Fuller, J.B., Barnett, T., Hester, K., Relyea, C. and Frey, L. (2007), “An exploratory examination of voice behavior from an impression management perspective", Journal of Managerial Issues, Vol. 19 No. 1, pp. 134-151.

Galie, P.J. and Bopst, C. (2006), "Machiavelli \& modern business: realist thought in contemporary corporate leadership manuals", Journal of Business Ethics, Vol. 65 No. 3, pp. 235-250.

Grosser, T.J., Obstfeld, D., Choi, E.W., Woehler, M., Lopez-Kidwell, V., Labianca, G. and Borgatti, S.P. (2018), "A sociopolitical perspective on employee innovativeness and job performance: the role of political skill and network structure", Organization Science, Vol. 29 No. 4, pp. 612-632.

Guadagno, R.E. and Cialdini, R.B. (2007), "Gender differences in impression management in organizations: a qualitative review”, Sex Roles, Vol. 56 Nos 7/8, pp. 483-494.

Hochwater, W.A., Pearson, A.W., Ferris, G.R., Perrewé, P.L. and Ralston, D.A. (2000), "A reexamination of Schriesheim and Hinkin's (1990) measure of upward influence”, Educational and Psychological Measurement, Vol. 60, pp. 755-771.

Hyde, J.S. (2005), “The gender similarities hypothesis”, American Psychologist, Vol. 60, pp. 581-592, doi: 10.1037/0003-066X.60.6.581.

Jones, E.E. (1990), Interpersonal Perception, W. H. Freeman, New York.
Leapfrogging Behavior at Work 
PR

49,8

Kalnbach, L.R. and Hinsz, V.B. (1999), "A conceptualization and test of the influences of individual differences in goal-setting situations", Journal of Applied Social Psychology, Vol. 29 No. 9, pp. 1854-1878.

Kumar, K. and Beyerlein, M. (1991), "Construction and validation of an instrument for measuring ingratiatory behaviors in organizational settings", Journal of Applied Psychology, Vol. 76 No. 5, pp. 619-627.

Leary, M.R. (1983), "A brief version of the fear of negative evaluation scale", Personality \& Social Psychology Bulletin, Vol. 9 No. 3, pp. 371-375.

Levi-Strauss, C. (1969), The Elementary Structures of Kinship, Beacon, Beacon, Boston, MA.

Long, D.M., Baer, M.D., Colquitt, J.A., Outlaw, R. and Dhensa-Kahlon, R.K. (2015), "What will the boss think? The impression management implications of supportive relationships with star and project peers", Personnel Psychology, Vol. 68 No. 3, pp. 463-498.

Martin, R., Thomas, G., Legood, A. and Dello Russo, S. (2018), "Leader-member exchange (LMX) differentiation and work outcomes: conceptual clarification and critical review", Journal of Organizational Behavior, Vol. 39 No. 2, pp. 151-168.

Meece, J.L. and Courtney, D.P. (1992), "Gender differences in students' perceptions: consequences for acheivement-related choices", in Schunk, D.H. and Meece, J.L. (Eds), Student Perceptions in the Classroom, Lawrence Erlbaum Associates, Mahwah, NJ, pp. 209-228.

Mowday, R. (1978), "The exercise of upward influence in organizations", Administrative Science Quarterly, Vol. 23 No. 1, pp. 137-156.

Munyon, T.P., Summers, J.K., Thompson, K.M. and Ferris, G.R. (2015), "Political skill and work outcomes: a theoretical extension, meta-analytic investigation and agenda for the future", Personnel Psychology, Vol. 68 No. 1, pp. 143-184.

Piccolo, R.F., Bardes, M., Mayer, D.M. and Judge, T.A. (2008), "Does high quality leader-member exchange accentuate the effects of organizational justice?", European Journal of Work and Organizational Psychology, Vol. 17 No. 2, pp. 273-298.

Pishwa, H. (2009), "Linguistic structures as cues for social cognitive functions", in Pishwa, H. (Ed.), Language and Social Cognition: Expression of the Social Mind, Mouton de Gruyter, New York, pp. 1-12.

Podsakoff, P.M., MacKenzie, S.B., Lee, J.Y. and Podsakoff, N.P. (2003), "Common method bias in behavioral research: a critical review of the literature and recommended remedies", Journal of Applied Psychology, Vol. 88, pp. 879-903.

Rotondo, D. (1999), "Individual-difference variables and career-related coping", The Journal of Social Psychology, Vol. 139 No. 4, pp. 458-471.

Scandura, T.A., Graen, G.B. and Novak, M.A. (1986), "When managers decide not to decide autocratically: an investigation of leader-member exchange and decision influence", Journal of Applied Psychology, Vol. 71 No. 4, p. 579.

Schilit, W.K. (1986), "An examination of individual differences as moderators of upward influence activity in strategic decisions", Human Relations, Vol. 39 No. 10, pp. 933-953.

Schneider, B. (1983), "Interactional psychology and organizational behavior", Research in Organizational Behavior, Vol. 5, pp. 1-31.

Sedikides, C., Herbst, K.C., Hardin, D.P. and Dardis, G.J. (2002), "Accountability as a deterrent to selfenhancement: the search for mechanisms", Journal of Personality and Social Psychology, Vol. 83 No. 3, pp. 592.

Shore, L.M. and Coyle Shapiro, J.A. (2003), "Editorial: new developments in the employee organization relationship", Journal of Organizational Behavior, Vol. 24 No. 5, pp. 443.

Sibunruang, H. and Capezio, A. (2016), "The effects of Machiavellian leaders on employees' use of upward influence tactics: an examination of the moderating roles of gender and 
perceived leader similarity", in Vigoda-Gadot, E. and Drory, A. (Eds), Handbook of Organizational Politics: Looking Back and to the Future, Edward Elgar, Cheltenham, UK, pp. 272-292.

Sparr, J.L. and Sonnentag, S. (2008), "Fairness perceptions of supervisor feedback, LMX, and employee well-being at work", European Journal of Work and Organizational Psychology, Vol. 17 No. 2, pp. 198-225.

Sparrowe, R.T. and Emery, C. (2015), "Tracing structure, tie strength, and cognitive networks in LMX theory", in Bauer, T.N. and Erdogan, B. (Eds), The Oxford Handbook of Leader-Member Exchange, Oxford University Press, New York, pp. 293-310.

Spector, P.E. (2006), "Methods variance in organizational research: truth or urban legend?", Organizational Research Methods, Vol. 9 No. 2, pp. 221-232.

Steers, R.M. and Braunstein, D.N. (1976), "A behaviorally-based measure of manifest needs in work settings", Journal of Vocational Behavior, Vol. 9 No. 2, pp. 251-266.

Stewart, G.L. and Carson, K.P. (1997), "Moving beyond the mechanistic model: an alternative approach to staffing for contemporary organizations", Human Resource Management Review, Vol. 7 No. 2, pp. 157-184.

Tedeschi, J.T., Schlenker, B.R. and Linkskold, S. (1972), "The exercise of power and influence: the source of influence", in Tedeschi, J.T. (Ed.), Social Influence Processes, Aldine, Chicago, pp. 287-345.

Terborg, J.R. (1981), "Interactional psychology and research on human behavior in organizations", Academy of Management Review, Vol. 6 No. 4, pp. 569-576.

Terpstra-Tong, J. and Ralston, D.A. (2002), "Moving toward a global understanding of upward influence strategies: an Asian perspective with directions for cross-cultural research", Asia Pacific Journal of Management, Vol. 19 Nos 2/3, pp. 373-404.

Treadway, D.C., Hochwarter, W.A., Kacmar, C.J. and Ferris, G.R. (2005), "Political will, political skill, and political behavior", Journal of Organizational Behavior, Vol. 26 No. 3, pp. 229-245.

Triplett, N. (1898), "The dynamogenic factors in pacemaking and competition", American Journal of Psychology, Vol. 9 No. 4, pp. 507-533.

Tse, H., To, M.L., Lam, C.K. and Lin, X.S. (2017), "Understanding the role of Machiavellianism in unfavorable LMX comparison processes", Academy of Management Proceedings, Academy of Management, Briarcliff Manor, NY, Vol. 2017 No. 1, p. 12551.

Turnley, W.H. and Bolino, M.C. (2001), "Achieving desired images while avoiding undesired images: exploring the role of self-monitoring in impression management”, Journal of Applied Psychology, Vol. 86 No. 2, pp. 351.

Van Maanen, J., Sorensen, J.B. and Mitchell, T.R. (2007), "The interplay between theory and method", Academy of Management Review, Vol. 32 No. 4, pp. 1145-1154.

Wang, P.Q., Kim, P.B. and Milne, S. (2017), "Leader-member exchange (LMX) and its work outcomes: the moderating role of gender", Journal of Hospitality Marketing \& Management, Vol. 26 No. 2, pp. 125-143.

Wayne, S.J., Liden, R.C., Graf, I.K. and Ferris, G.R. (1997), "The role of upward influence tactics in human resource decisions", Personnel Psychology, Vol. 50 No. 4, pp. 979-1006.

Weinberg, F.J. (2019), "How and when is role modeling effective? The influence of mentee professional identity on mentoring dynamics and personal learning outcomes", Group \& Organization Management, Vol. 44 No. 2, pp. 425-477.

Weinberg, F.J., Treviño, L.J. and Cleveland, A.O.S. (2019), "Gendered communication and career outcomes: a construct validation and prediction of hierarchical advancement and nonhierarchical rewards", Communication Research, Vol. 46 No. 4, pp. 456-502.

Westphal, J.D. and Stern, I. (2006), "The other pathway to the boardroom: interpersonal influence behavior as a substitute for elite credentials and majority status in obtaining board appointments", Administrative Science Quarterly, Vol. 51 No. 2, pp. 169-204.
Leapfrogging Behavior at Work 
PR

49,8

1786

Wood, W., Christensen, P., Hebl, M. and Rothgerber, H. (1997), "Conformity to sex-typed norms, affect, and the self-concept”, Journal of Personality and Social Psychology, Vol. 73, pp. 523-535, doi: 10. 1037/0022-3514.73.3.523.

\section{Further reading}

Dweck, C.S. (1986), "Motivational processes affecting learning”, American Psychologist, Vol. 41 No. 10, p. 1040.

Sutherland, E. and Veroff, J. (1985), “Achievement motivation and set roles”, in O'Leary, V.E., Under, R.K. and Wallston, B.S. (Eds), Women, gender, and social psychology, Hillsdale, NJ, pp. 101-128.

\section{Corresponding author}

Patricia G. Martinez can be contacted at: patricia.martinez@lmu.edu

For instructions on how to order reprints of this article, please visit our website: www.emeraldgrouppublishing.com/licensing/reprints.htm Or contact us for further details: permissions@emeraldinsight.com 